\title{
Audiência Pública Simulada: Uma ferramenta multidisciplinar para o ensino de Ciências envolvendo Questões Sociocientíficas e Ambientais na Região Amazônica
}

\author{
Simulated Public Audience: A multidisciplinary tool for teaching science involving \\ Socioscientific and Environment Issues related to the Amazon Region
}

\author{
Marcondes Luiz da Silva Azevedo (i) https://orcid.org/0000-0002-2445-6964 \\ Instituto Federal de Educação, Ciência e Tecnologia do Pará - IFPA \\ e-mail - marcondes.qp@gmail.com \\ lata Anderson Ferreira de Araújo (iD) https://orcid.org/0000-0002-1965-0682 \\ Universidade Federal do Oeste do Pará - UFOPA \\ e-mail -iata.afaraujo@gmail.com
}

Alex de Jesus Pinheiro (iD https://orcid.org/0000-0001-5359-1623

Instituto Federal de Educação, Ciência e Tecnologia do Pará - IFPA

e-mail - alexjpinheiro@gmail.com

\section{Resumo}

No intuito de oportunizar um espaço em que os alunos desenvolvam um pensamento crítico e reflexivo, além do engajamento destes com temas sociocientíficos e ambientais, objetivou-se incrementar os movimentos argumentativos dos alunos com aspectos conceituais, técnicos e de seu cotidiano dentro do ensino de ciências, exatas e humanas, por meio do debate entre os alunos. Para tanto, foi realizada uma Audiência Pública Simulada com o tema: Instalação da mineração na região do Baixo Amazonas, em Óbidos-PA, rica em Bauxita (óxido de alumínio). Além da produção de um texto discursivoargumentativo, por considerar a linguagem escrita como fundamental na formação do conhecimento científico escolar. A avaliação do debate foi baseada na Tríade Argumentativa A-CA-R, utilizando a metodologia da Análise Textual do Discurso ATD, buscando evidenciar os movimentos argumentativos expressos no discurso da audiência. Como principais resultados, a estratégia de ensino se mostrou útil à negociação dos argumentos entre os alunos frente às Questões Sociocientíficas e Ambientais, gerados pela produção da bauxita na região amazônica.

Palavras-chave: Argumentação. Meio Ambiente. Contexto Social. Abordagem Educacional. 


\begin{abstract}
In order to provide a space in which students develop critical and reflective thinking, in addition to engaging them with socioscientific and environmental themes, the objective was to increase students' argumentative movements with conceptual, technical and everyday aspects within science education accurate and humane through debate among students. To this end, a Simulated Public Audience was held with the theme: Installation of mining in the region of Baixo Amazonas, in Óbidos-PA, rich in Bauxite (aluminum oxide). In addition to the production of argumentative text, for considering written language as fundamental in the formation of scientific knowledge in school classrooms. The debate's evaluation was based on the Argumentative Triad A-AA-R, using the Textual Discourse Analysis (TDA) methodology, seeking to highlight the argumentative movements expressed in the audience's speech. As main results, the teaching strategy proved to be useful for negotiating arguments between students in the face of Socioscientific and Environmental Issues regarding the production of bauxite to the Amazon region.
\end{abstract}

Keywords: Argumentation. Environmental. Social Context. Educational Approach.

\title{
Introdução
}

Estudos recentes no ensino de ciências vêm mostrando a importância da inserção dos alunos em ambientes que promovam a interação social entre si e debatam aspectos socioambientais (SIMONNEAUX, 2007; SASSERON, 2008; JIMÉNEZALEIXANDRE, 2010; PENHA, 2012; SILVA, 2017; AZEVEDO \& SILVA, 2018). Esses autores concordam que o ensino de ciência deve buscar meios de estruturar suas atividades de modo a colocar os estudantes como protagonistas da produção do conhecimento em sala de aula. Como expostos por Silva et al. (2017), o ensino e a aprendizagem de ciências ultrapassa a compreensão e o uso de conceitos e modelos científicos, deve-se incluir a apropriação e a participação dos alunos nas práticas científicas, levando o aluno a se aproximar dessa cultura e ter elementos na resolução de questões da sociedade contemporânea.

Dentro dessa perspectiva, Penha (2012) e Silva (2017) abordam as Questões Sociocientíficas (QSC) no Ensino de Ciências por meio da habilidade cognitivolinguística da argumentação ao evidenciarem a possibilidade de desenvolver tanto habilidades pessoais, relacionadas à formação do indivíduo, quanto coletivas, voltadas para a tomada de decisões que envolvem a sociedade como um todo, além do fato dos alunos poderem relacionar aspectos sociais dos quais eles mesmos estão inseridos.

A habilidade da argumentação no ensino de ciências é vista nas obras dos seguintes autores (PERELMAN, 2004; CHIARO; LEITÃO, 2005; JIMÉNEZALEIXANDRE, 2010; LIRA;LEITÃO, 2016; ADÚRIZ-BRAVO; REVEL, 2017) como importante base para produção, comunicação e avaliação de conhecimento científico gerado em sala de aula, além da contribuição para a formação de cidadãos com pensamento crítico e reflexivo acerca das diversas questões que os envolvem como sociedade. Nesse sentido, Silva (2017) destaca a capacidade 
dessa abordagem em promover o desenvolvimento do pensamento crítico dos discentes, compreendido como a aplicação dos conhecimentos científicos às Questões Socioambientais no seu cotidiano e na localidade em que vive.

Perelman (2004) define a argumentação como sendo a ação sobre um auditório, por meios discursivos, com o intuito de persuadi-lo ou aumentar sua adesão às teses apresentadas. Chiaro e Leitão (2005) defendem que a argumentação está presente no dia-a-dia dos seres humanos em situações que necessitam o exame e negociação de divergência entre posicionamento por meio de diálogo, e que leve a ponderação/reflexão das justificativas e conclusões a respeito de determinado tema, resultando na tomada de decisão. Jiménez-Aleixandre (2010) define a argumentação no ensino de ciências como a capacidade de avaliar enunciados com base em provas, destaca como elemento indissociável da argumentação a avaliação de conhecimentos à luz de evidências disponíveis.

Neste sentido, verifica-se que os temas sociocientíficos e ambientais podem ser abordados a partir de atividades que associem a habilidade cognitivo-linguística da argumentação às Questões Sociocientíficas (QSC), e aos aspectos relacionados ao Meio Ambiente. No entanto, é importante planejar a aplicação dessas atividades por dinâmicas que, como já exposto, coloque os alunos como protagonistas da produção de conhecimento. Mitchell (2000) defende a estratégia de ensino por Role-Play (atividades de encenação), como forma de trazer os estudantes aos debates acadêmicos como método de aprendizagem por meio do diálogo.

Dentro desse contexto, este trabalho trata-se de uma investigação empírica planejada a partir de uma atividade de cunho multidisciplinar, baseada na estratégia de ensino por Role-Play - a Audiência Pública Simulada (APS). O objetivo principal é analisar os movimentos argumentativos, emergentes na Audiência Pública Simulada ao abordar Questões Sociocientíficas e Ambientais. Para suscitar o debate, partimos do tema gerador: a produção mineral na região amazônica pela extração da bauxita (óxido de alumínio), por considerar a variedade de conteúdos que podem ser abordados. Bem como, a partir do tema em questão, possibilitar aos alunos o desenvolvimento de habilidades de pesquisar, estruturar argumentos, e expressar o conhecimento adquirido.

\section{Desenvolvimento}

\section{Habilidades Cognitivo-Linguística da Argumentação}

As habilidades cognitivo-linguísticas, conforme Azevedo e Silva (2018), são habilidades do pensamento para produção textual, seja ela oral ou escrita, tais como: descrever, resumir, definir, justificar, explicar e argumentar, sendo transversal a quaisquer áreas do currículo, portanto interdisciplinar. A argumentação remete a dimensão dialógica-interacional que visa ao convencimento do interlocutor, por meio de signos que contenham intenção comunicativa, ou seja, transmitir e comunicar suas ideias a um interlocutor, mesmo que seja ele próprio. Jiménez-Aleixandre (2011) define a argumentação como a capacidade de avaliar enunciados com base em provas, já o grupo Lectura y Escritura en Enseñanza de las Ciencias (LIEC) da Universidade Autônoma de Barcelona define argumentação como uma atividade social, intelectual e verbal que serve para justificar ou refutar uma opinião e que consiste 
em emitir declarações tendo em conta um receptor e a finalidade de convencê-lo. Nesse sentido, Chion et al. (2014) destacam a argumentação científica escolar como um procedimento cognitivo-linguístico - que dá lugar a produção de um texto - levando em consideração quatro componentes: pragmática (a adequação ao contexto), retórica (a intenção de persuadir o receptor), teórica (o ajuste ao modelo teórico de referência) e a lógica (a estrutura sintática do texto).

A argumentação na perspectiva da retórica, conforme Perelman (2004), é ação sobre um auditório, por meios discursivos, ou seja, a arte de falar (ou escrever) de modo persuasivo com o intuito de conquistar ou aumentar sua adesão às teses que se apresenta ao seu assentimento.

Na dimensão lógica, Johnson e Blair (2017) explica que a argumentação tem a função é desenvolver parâmetros, critérios e procedimentos para a análise, interpretação e avaliação do discurso no cotidiano. O conceito de argumentação na perspectiva de Toulmin (2006) se destina à produção de proposições para apoiar uma conclusão, ou seja, afirmações que estejam sustentadas por evidências e justificativa(s) suficientes e relevantes para dar solidez à conclusão, conforme o modelo Padrão de Argumento - TAP.

A argumentação no âmbito da dialética se assenta na interação entre pontos de vistas (posicionamentos) opostos, como em debates e discussões, no intuito de produzir melhores decisões. Para Mendonça \& Justi (2013) "a dialética enfatiza o procedimento envolvido na construção de um argumento, baseado no contexto dessa produção". Chiaro e Leitão (2005) defendem que a argumentação está presente no dia-a-dia dos seres humanos em situações que necessitam o exame e a negociação de divergência entre opiniões e posicionamento por meio de diálogo, e que leve a ponderação/reflexão das justificativas e conclusões a respeito de determinado tema resultando na tomada de decisão. Neste sentido, segundo Leitão (2011) a argumentação é um discurso de natureza dialógica, mesmos em situações interna (consigo mesmo(a)) como na escrita de um texto, ou mesmo em grupo com enunciados orais ou escritos, ou ainda em diálogos e discussões com demais, em que precisamos tomar uma decisão, expor nossos pontos de vista, justificar nossas posições, julgar nossas opiniões frente aos argumentos expostos por terceiros.

A dimensão pragmática da argumentação, conforme Chion et al. (2014), além das demais dimensões, envolve também o contexto, os conhecimentos e os conceitos em que os conflitos estão inseridos.

\section{Movimentos argumentativos - Tríade Dialógica-Discursivas: A-CA-R}

No movimento dialógico-argumentativo, Lira e Leitão (2016) apresentam a tríade dialógica-discursivas A-CA-R (argumento, contra-argumento e resposta) representado pela figura 1 - como a dinâmica do diálogo que leva a negociação do posicionamento em questão, envolvendo movimento propositivo, opositivo e de resposta.

Segundo estes os autores, o movimento que emite um argumento, ou seja, o movimento propositivo apresenta os pontos de vistas (PV) que fixam um posicionamento sobre um tema ou assunto e a justificação $(\mathrm{J})$ que fundamenta esses pontos de vistas, configurando-se como argumentos (A). O movimento opositivo é o posicionamento que diverge e coloca em dúvida o argumento 
proferido, contestando-o diretamente ou apresentando elementos que dão sustentação a perspectivas contrárias. Trata-se, portanto, de argumentos que apresentam ponto de vista e justificativas, mas em sentido contrário ao argumento do proponente, por esse motivo é denominado de Contra-Argumento (CA).

Movimento de Resposta $(R)$ é uma reação imediata ou remota do interlocutor ao contra-argumento ou ao argumento, podendo ser de terceiros ou do enunciador do argumento inicial. A resposta tem um caráter avaliativo na medida em que captura eventuais impactos (ajustes, mudanças, negação ou reafirmação) elaborados no contra-argumento em função do argumento inicial. Trate-se da reação do primeiro ou de terceiros a essa intervenção que, por sua vez, pode constituir em novo argumento, iniciando uma nova negociação que viabiliza a construção do conhecimento que vai desde mudanças sutis no discurso, sem alterar o ponto de vista inicial, até mudanças totais do ponto de vista inicial em favor do contraargumento.

Assim, a resposta pode ser classificada em três categorias, a saber: Resposta de destituição do contra-argumento, Resposta integrativa e Resposta de destituição do argumento. A resposta de destituição do contra-argumento, ou oposição ao contra-argumento, ocorre com a preservação do argumento inicial sem alteração; já na resposta integrativa somam-se partes do argumento e partes do contraargumento modificando-se, assim, o argumento inicial; e por fim, a resposta de destituição do argumento se dá pela aceitação do contra-argumento integralmente, retirando-se, assim, o argumento inicial. Abaixo segue um esquema do movimento argumentativo, representado na figura 1.

Figura 1- Tríade argumentativa (A-CA-R)

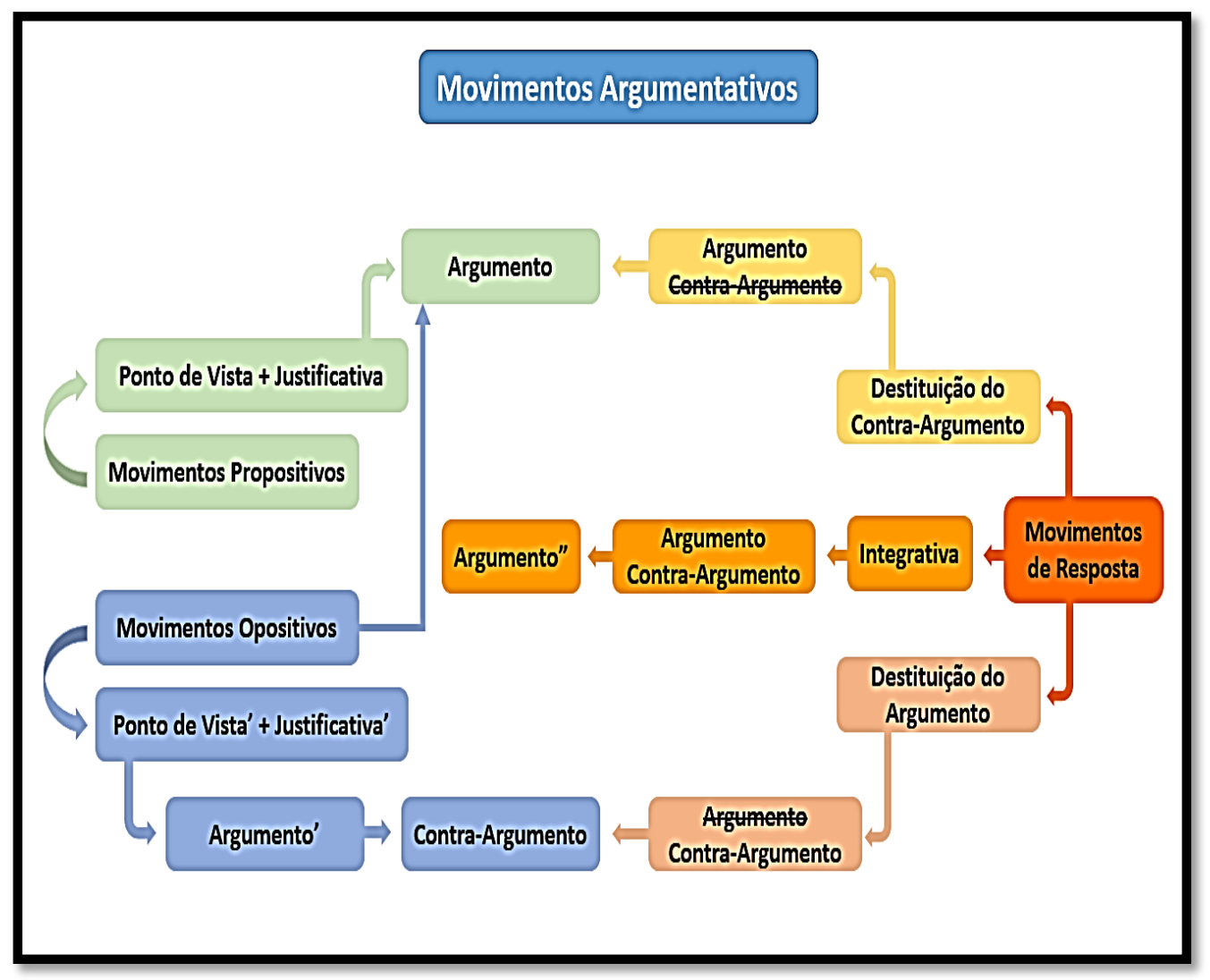

Fonte: Autoria própria 


\section{Questões Sociocientíficas e Ambientais}

Há algum tempo, pesquisas desenvolvidas por Sasseron (2008), JiménezAleixandre \& Gallástegui (2011), Azevedo \& Silva (2018), entre outros, sobre a dimensão discursiva no ensino-aprendizagem de ciências vêm expondo a necessidade de colocar o aluno como protagonista da produção do conhecimento, bem como valorizar o conhecimento prévio que os alunos já possuem e comparálo ao conhecimento científico já existente para a produção do seu próprio conhecimento, como apresentado a seguir:

\footnotetext{
Para aprender Ciência é necessário aprender a falar, escrever e ler Ciência de maneira significativa, o que implica também em aprender a reconhecer as diversas maneiras de se expressar um mesmo significado, as diferenças entre a linguagem cotidiana e a linguagem científica e as principais características de cada tipo de discurso. (Jorge \& Puig, 2000, p. 2035).
}

Nesse sentido, o conhecimento prévio que o aluno traz consigo é arraigado de concepções de mundo que ele possui, que por vezes precisam ser ressignificados de acordo com os argumentos científicos aceitos pela comunidade científica. No entanto, a ressignificação desses conceitos, conforme Azevedo \& Silva (2018), deveria ser realizada com bases na autorregulação do seu pensamento, o que inclui um pensamento crítico e reflexivo acerca dos aspectos sócio-históricos que Ihes cercam.

O pensamento crítico é definido por Jiménez-Aleixandre (2010, p. 121) como a capacidade de reflexão acerca de Questões Sociocientíficas e a intervenção na sociedade, entendendo como assuntos desse tipo aquelas questões sociais que demandam decisões políticas, éticas, econômicas, ambientais, dentre outros. Desse modo, o pensamento crítico deve permear às Questões Sociocientíficas definidas por Sadler (2004) e Simonneaux (2007) como questões controversas em que visões concorrentes competem com diferentes partes, tendo implicações em um ou mais dos seguintes campos: Biologia, Sociologia, Ética, Política, Economia e Meio Ambiente.

Para Jiménez-Aleixandre e Pereiro-Muñoz (2002), as QSC são problemas sociais relevantes, que apresentam implicações éticas como os problemas ambientais relativos à gestão dos recursos naturais. Nessa perspectiva, Jiménez-Aleixandre (2010) explica que as Questões Sociocientíficas se baseiam nas, i) dimensões sociais: relacionadas às estruturas sociais, por exemplo, a convivência, a economia, o bem-estar e o consumo; ii) dimensões éticas: decisões relacionadas ao que é aceitável ou não, por exemplo, clonagem humana, biopirataria e apropriação de recursos genéticos; iii) dimensões políticas: que afetam os direitos e liberdades das pessoas, por exemplo, os debates sobre a informação de que o produto a ser consumido é transgênico e; iv) dimensões ambientais: voltadas para a proteção e a melhoria dos recursos naturais, por exemplo, as discussões relativas à ecologia e ao aquecimento global.

As questões socioambientais no ensino de ciências podem ser discutidas em sala de aula de forma interdisciplinar, que na visão de Cesco (2011) é um desafio mais intelectual no sentido de fazer colaborar disciplinas que não vão enxergar os mesmos níveis de realidade. Monteiro (2018, p. 82), analisa as questões ambientais como um saber posicionado: abordar situações de conflito deveria ser 
uma prática sempre carregada de tensão, uma vez que, por definição, um conflito pressupõe lados, pelo menos dois, em oposição.

\title{
Audiência Pública Simulada
}

A estratégia de ensino por Role-Play (atividades de encenação) defendido por Mitchell (2000) e Calzolari et al. (2018), como a aplicação de atividades dinâmicas, em que os estudantes desempenham papéis determinados por uma simulação de situações possíveis de acontecerem no mundo real. Este tipo de atividade, de acordo com (McSHARRY; JONES, 2000), no ensino de ciências permite estimular a criatividade e evidenciar a responsabilidade dos estudantes nos processos de ensino e aprendizagem, tratar questões éticas, morais e, ainda, abordar conhecimentos científicos curriculares.

A simulação de situações da argumentação pública, como forma de encenação defendida por Mitchell (2000), representa um modelo de debate acadêmico que promete resgatar mais plenamente o potencial dialógico como método de aprendizagem por meio da argumentação. Nesse sentido, Monteiro (2018), enfatiza que o uso da APS é uma escolha que permite uma maior compreensão do caráter político de um conflito, além de propiciar um espaço de diálogo para tomada de decisão pelo debate com os atores sociais. Os papéis sociais distribuídos numa simulação de debates públicos, expressos por Mitchell (2000), podem ser mais variados e complexos de acordo com o tema escolhido para a encenação.

César (2011) esclarece que nas audiências públicas oficiais os órgãos públicos estão abertos para ouvir a todos e a colaborarem na busca de uma solução que traga menos danos à sociedade e ao ambiente. $\mathrm{O}$ mesmo autor, em relação às audiências públicas simuladas, aponta que os diferentes atores sociais presentes na audiência pública não possuem suas falas enquadradas em personagens fixos, uma vez que a sociedade é composta por inúmeros atores. Para o seu regimento, deve ser elaborado um regulamento para gerir a audiência pública, disciplinando a forma como se dará o diálogo com a sociedade. Assim, para a realização da audiência pública deverá ser consignado:

\begin{abstract}
a) quem presidirá a audiência pública; b) data de início e término dos trabalhos; c) pessoas que serão notificadas a comparecer à audiência pública; d) número de pessoas que serão ouvidas (defensores e opositores em número igualitário) e respectivo prazo de cada um; e) prazo para a indicação de pessoas a serem ouvidas; e) forma como a população poderá se manifestar - se por escrito ou oralmente, neste caso, indicando o prazo de cada um; g) ampla divulgação pelos meios de comunicação; h) a forma como será efetuado o registro dos trabalhos (ata, vídeo e áudio); i) esclarecer se será entregue recomendações aos presentes; j) a forma como será divulgada a conclusão da audiência pública; etc. (CÉSAR, 2011, p. 360).
\end{abstract}

\section{Metodologia}

\section{Contexto e Sujeitos da Pesquisa}

Este trabalho trata-se de uma investigação empírica, realizada numa sequência de aulas integradas entre as disciplinas de química, geografia e português, portanto uma atividade de cunho multidisciplinar, envolvendo alunos da Educação Básica 
de Nível Médio Integrado do Instituto Federal do Pará, Campus Óbidos. O objetivo principal é promover um ambiente em que os alunos possam ser protagonistas da produção do conhecimento dentro de um contexto dialógico, em sala de aula, ao abordar e aplicar conceitos técnicos, científicos e ambientais, numa realidade que eles façam parte, ou seja, na localidade, região e na sociedade em que eles vivem. Além disso, temos como objetivo metodológico analisar os movimentos argumentativos emergentes nas eventuais discussões entre os atores sociais vivenciados pelos estudantes sobre as Questões Sociocientíficas (QSC) e ambientais.

Para tanto, buscamos desenvolver uma atividade que associe a habilidade cognitivo-linguística da argumentação às Questões Sociocientíficas (QSC) e ambientais. Assim, encontramos na literatura a estratégia de ensino por Role-Play (atividades de encenação), aplicada nos trabalhos de Mitchell (2000), McSharry \& Jones, (2000), e Calzolari et al. (2018), como atividades em que os estudantes desempenham papéis determinados por uma simulação de situações possíveis de acontecerem no mundo real. Além disso, as simulações e debates potencializam o trabalho coletivo interativo e a negociação, o que amplia sua possibilidade de realização em sala de aula, na perspectiva comunicativa (CALZOLARI et al., 2018).

Desse modo, para o desenvolvimento dessa intervenção foi pensada e elaborada uma atividade dialógica, por meio da Audiência Pública Simulada, por considerar que esta atividade apresenta o ambiente favorável para que os alunos possam, a partir de um tema em questão, desenvolver suas próprias habilidades para pesquisar, estruturar argumentos e expor o conhecimento gerado, além de negociar pontos de vistas distintos, embasados em conhecimentos teóricos e práticos.

O tema gerador desta atividade foi a problemática da produção industrial do alumínio pela extração da bauxita (óxido de alumínio) e os impactos socioambientais dessa extração na Floresta Amazônica. O tema foi desenvolvido a partir do seguinte questionamento: quais os impactos que a extração de bauxita na região do Baixo Amazonas pode provocar no cotidiano das pessoas e do meio ambiente? Desse modo, foi organizada a APS para debater a Instalação de uma empresa mineradora na região do Baixo Amazonas em Óbidos-PA - por ser rica em Bauxita (Óxidos de Alumínio).

Para a organização da APS, os alunos foram colocados em dois grupos de pontos de vistas opostos. Uma parte dos alunos "atores sociais" ficou a favor da instalação da mineradora na região, e outra parte se posicionou contra essa instalação. A atividade foi desenvolvida com duas turmas composta por 52 alunos do terceiro ano do Ensino Médio, divididos em diversos atores e grupos sociais, de modo que os papéis foram distribuídos conforme o quadro 1. 
Quadro 1- Atores sociais na Audiência Pública Simulada no IFPA - Campus Óbidos.

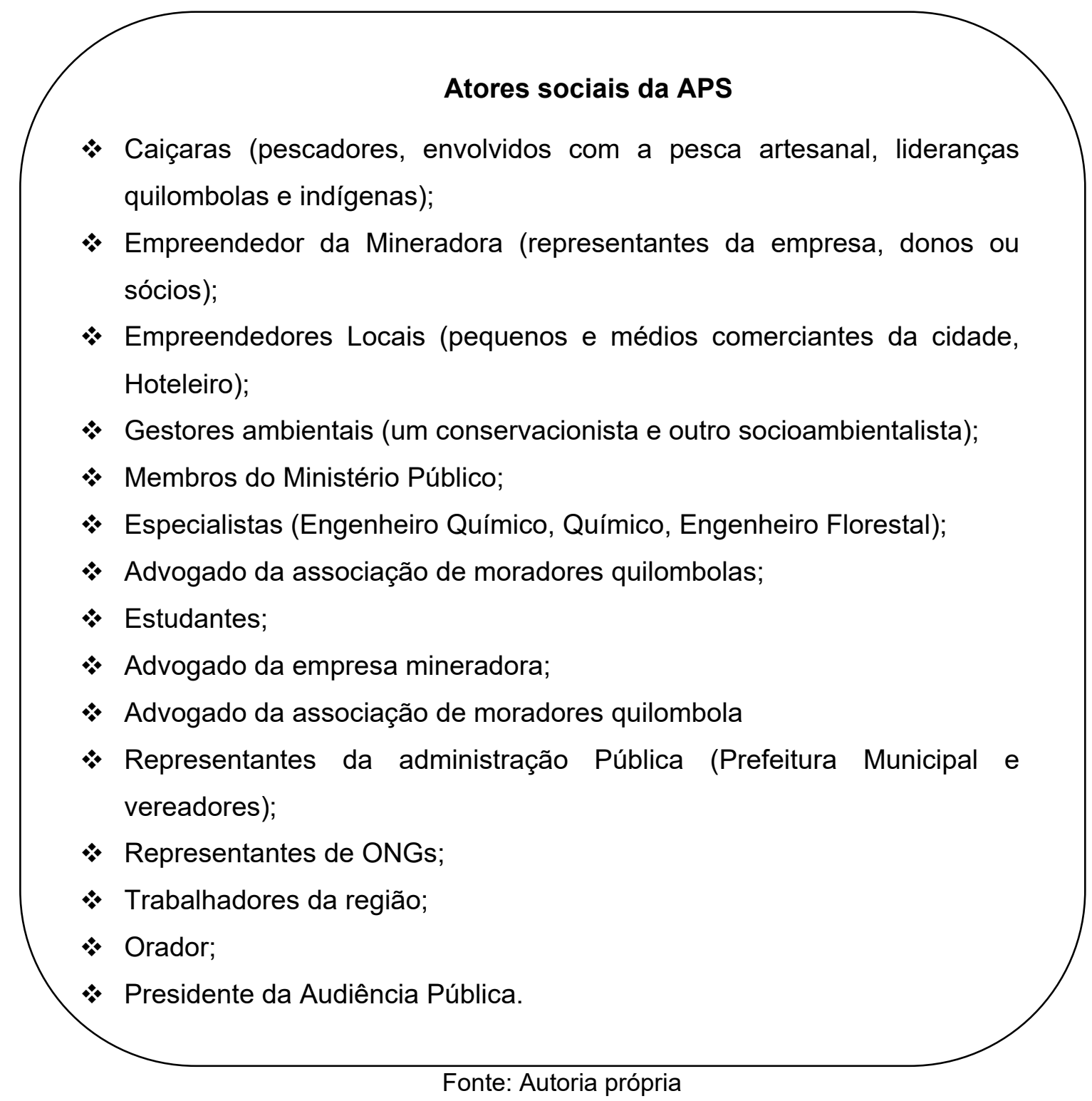

\section{Sequência Didática da APS}

A sequência didática para organizar a APS foi dividida em ações. As ações foram pensadas pelos professores de geografia, química e português, de modo a ter momentos de tomadas de decisões conjuntas, como a escolha do tema gerador, os conteúdos a serem trabalhados, a divisão dos alunos e seus atores sociais, e a organização da APS. O tempo de desenvolvimento de toda atividade foi de 4 semanas, contando a presença dos alunos numa audiência pública organizada pelo IBAMA na cidade de Óbidos-PA, o que ajudou bastante para os alunos terem ciência da dinâmica dessa atividade social. O tempo decorrido da audiência pública simulada desenvolvida foi de 3 horas e $45 \mathrm{~min}$, contou com a participação dos 52 alunos e a presença de uma plateia de mais 130 alunos dos $1^{\circ}$ e $2^{\circ}$ anos do Ensino Médio do IFPA.

Primeira ação: como trata-se de uma atividade multidisciplinar, é importante que o primeiro momento seja para discutir com os professores de disciplinas afins os conteúdos e conceitos que podem ser abordados. Nesse sentido, foi decidido 
organizar o tema abrangente aos diversos cursos técnicos oferecidos pela instituição e que afetam diretamente ou indiretamente a sociedade local. A partir dos diálogos docentes, decidimos trabalhar a temática da mineração na região, uma vez que permite o estudo de conceitos de diferentes áreas do conhecimento.

Segunda ação: Apresentar o tema aos alunos de forma integrada com os demais professores, evidenciando aspectos relacionados à importância da preservação ambiental, e a necessidade de produção de matéria-prima para a indústria em geral; indicamos documentários sobre os impactos ambientais, mineração; e solicitamos que pesquisassem sobre a dinâmica de uma Audiência Pública, principalmente sobre aquelas que tratam de temas socioambientais.

Terceira ação: Neste momento, organizamos os grupos com seus temas, seguido da distribuição dos personagens e posicionamentos a serem defendidos na APS, também foi explicada a utilização do Termo de Consentimento Livre e Esclarecido (TCLE) e dado um tempo para adesão do termo. Posteriormente, disponibilizamos um tempo hábil para pesquisa, adaptação cênica e organização dos argumentos.

Quarta ação: Realização da APS com a mesa de debate sobre a temática, na qual disponibilizamos recursos para apresentação dos estudos desenvolvidos pelos grupos de atores. É nesta ação que há a exposição dos dados, evidências e provas em forma da apresentação de depoimentos, documentos que os estudantes trazem para a audiência, dos debates gerados nas arguições. O registro dos dados da intervenção foi realizado por meio de gravação em áudio, vídeo (para compor o acervo pedagógico da instituição) e fotografia, assim como servir de coleta de dados para o presente trabalho.

Quinta ação: Solicitação para cada estudante produzir um texto dissertativoargumentativo com o tema em vigor.

\section{Natureza da Pesquisa}

Devido às peculiaridades da atividade Role-Play, a qual é organizada em um contexto específico, podemos considerar que esta intervenção se enquadra nas abordagens qualitativas de pesquisa, perspectiva mais adequada para estudar alguns fenômenos sociais como os processos educativos, caracterizada por Bogdan e Biklen (1994). Dentre os diversos métodos de pesquisas de caráter qualitativo, utilizamos o estudo de caso, que segundo Ludke e André (2013) é o tipo de pesquisa que envolve a interpretação do fenômeno no contexto de modo a retratar a realidade; utiliza fontes de informação variadas; procura representar pontos de vista presentes numa situação social.

Os dados coletados na proposta de APS estão dentro do espectro do discurso textual, verbal e não verbal, e desse modo foram tratados por meio da Análise Textual Discursiva (ATD), que de acordo com Moraes e Galiazzil (2007) constituise de um ciclo dividido em três momentos, quais sejam: (i) unitarização; (ii) categorização; (iii) comunicação. Moraes e Galiazzil (2007) diz que no momento da (i) unitarização, o pesquisador, faz a leitura dos textos ou falas que constituem seu material de análise, e deles retira trechos que expressem significados e representem o fenômeno estudado. Em seguida, agrupa os trechos em (ii) categorias, que surgem à medida que, dos textos desconstruídos, o pesquisador começa a estabelecer relações, ou podem ser estabelecidas a partir da teoria que subsidiará a análise. Encerrando o ciclo está o processo de (iii) comunicação dos 
resultados que se dá a partir da construção de textos que expressem o conjunto de significados construídos durante a análise.

\section{Resultados e Discussões}

A captura dos dados ocorreu durante a APS com registro da discussão se dando por meio de gravação de áudio e vídeo. Contudo, ainda durante a organização da atividade, foi apresentado e explicado aos alunos o Termo de Consentimento Livre e Esclarecido (TCLE) de modo que fosse possível o trato e divulgação das imagens e do discurso dos alunos na atividade. Os dados analisados são fragmentos dos discursos dispostos em turnos, coletados após a apresentação da mesa com a fala do presidente da mesa e dos demais convidados. Nesses registros, buscamos identificar o movimento argumentativo (A-CA-R), como: questionamentos, pontos de vistas, contribuições; réplica, respostas por parte dos componentes da mesa; e tréplica. $\mathrm{Na}$ figura 2 são apresentamos alguns momentos da Audiência Pública Simulada ocorrida no auditório do IFPA Campus Óbidos.

\section{Primeiro momento de análise do movimento argumentativo}

Estudante - Nós sabemos que os impactos ambientais são vários com a implantação da mineradora, inclusive tem "estudos e universidade que indica" a contaminação dos peixes por metais pesados, e nós que vivemos essencialmente da alimentação do peixe iremos nos prejudicar com essa atividade. (Argumento: ponto de vista e justificativa, apresentam dados).

Ambientalista relator da EIA-RIMA: $O$ estudo que fizemos levou em consideração os laudos de especialistas de várias áreas, e verificamos que há uma população pequena de peixes que possuem metais pesados em seus organismos, contudo, os estudos não são suficientes para determinar que as causas dessa contaminação pontual sejam os metais existentes na camada mineral no subsolo, haja vista que as chuvas e os igarapés por si só carreiam muitos compostos para o Rio Amazonas, ou seja, é inconclusivo. (Contraargumento: ponto de vista e justificativa, apresentando um movimento opositivo ao argumento colocado anteriormente).

Estudante - Como que é inconclusivo, se uma pequena parte de matéria orgânica e mineral carregada pela chuva, como o senhor está colocando, é capaz de contaminar uma pequena população, imagine nos milhares de metros cúbicos despejados no rio? (Resposta de destituição do contra-argumento: numa tentativa de preservar o argumento inicial).

Empreendedor: No caso do empreendimento que iremos gerir, haverá a área destinada a rejeitos que não irá direto para o rio, assim não haverá contaminação, pelo menos diretamente. (Resposta de destituição do argumento: apesar de não concordar com o contra-argumento, dá uma solução que não concorda com o argumento inicial). 
Figura 2- Audiência Pública Simulada no IFPA - Campus Óbidos.

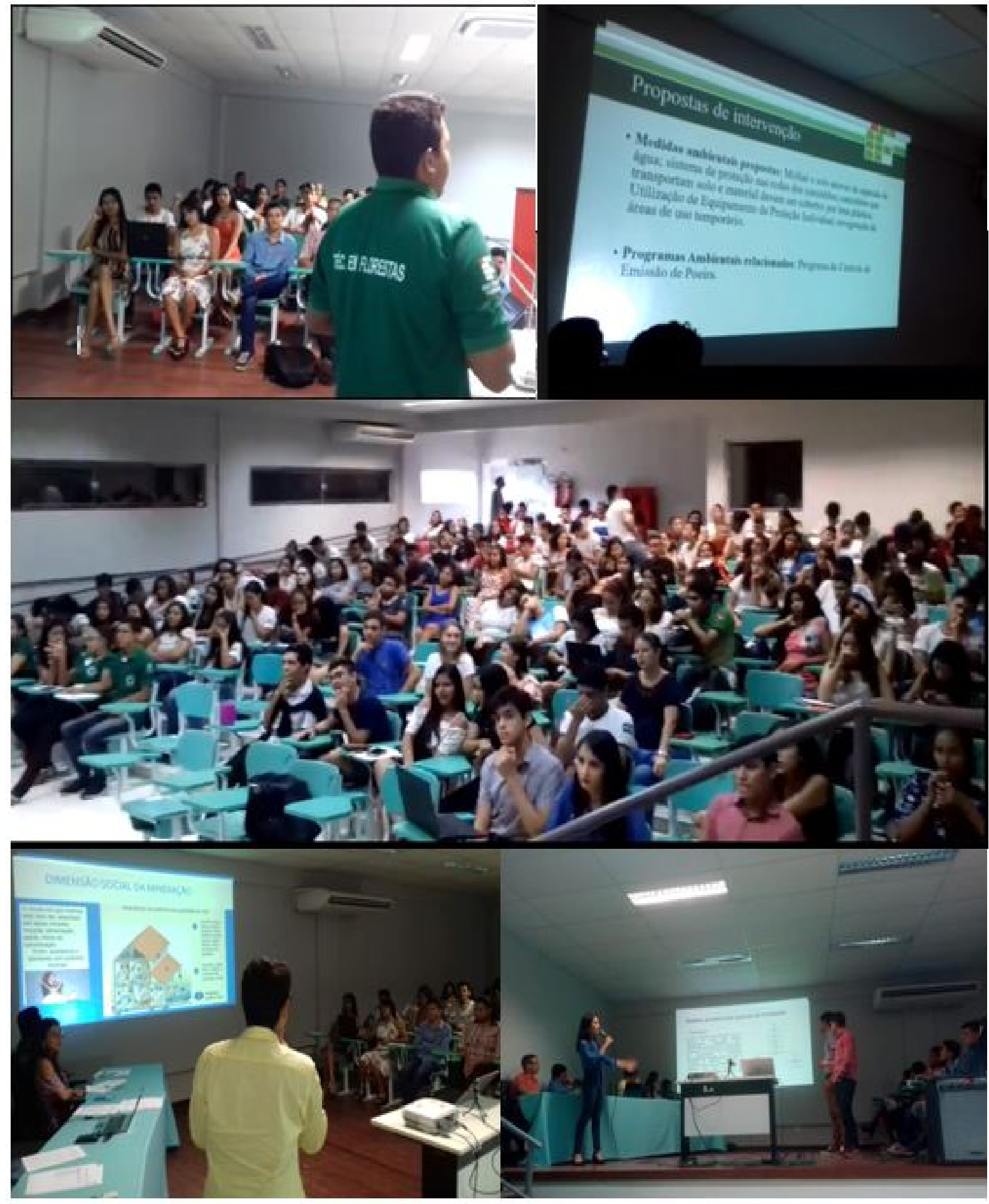

Fonte: Autoria própria

\section{Segundo momento de análise do movimento argumentativo}

Advogada dos Moradores Quilombolas - Os moradores de nossa comunidade estão indignados com esta proposta, não nos consultaram, estão nos ignorando e principalmente, ignorando nossa história, essas terras são nossa moradia e nosso sustento, vocês querem nos expulsar e nos matar dessa maneira. (Argumento: ponto de vista e justificativa, apresenta fatos). 
Empreendedor: Nossa empresa é uma empresa séria com 50 anos de atividade e nunca deixamos nenhum habitante desamparado, iremos indenizar cada habitante afetado, daremos uma bela casa na cidade, além de ofertar emprego com altos salários. A senhora quando fica doente deseja um hospital de qualidade, agora irá ter, além de escola e todo o progresso que a mineração pode ofertar. (Contraargumento: ponto de vista e justificativa, apresentando um movimento de contorno ao argumento exposto).

Advogada dos Moradores Quilombolas - Nós não queremos ser comprados e nem que apaguem nossa memória do mapa, o Governo tem obrigação de nos ofertar esses benefícios. (Resposta de destituição do contra-argumento: não há concordância com os pontos de vistas e justificativas expressas pelo empreendedor).

\section{Terceiro momento de análise do movimento argumentativo}

Morador de Óbidos: Você disse que $50 \%$ dos colaboradores seriam de capacitação técnica e o restante seria aproveitado na cidade, mas como acontece na cidade vizinha, quase nenhum trabalhador da mina é da cidade, na verdade tem muitos amigos meus que estão desempregados e outros que abriram bares para os "peões" da mineradora. (Argumento: ponto de vista e justificativa, apresenta dados).

Empreendedor: Como foi colocado $50 \%$ dos nossos funcionários serão da cidade de Óbidos-PA, isso já está no projeto, faz parte de nossa política, temos reconhecimento das ISOs, e é um comprometimento meu como presidente da empresa que você e vários cidadãos daqui estarão empregados em breve. (Contra-argumento: ponto de vista e justificativa, apresentando um movimento de contorno ao argumento exposto).

Morador de Óbidos: Eu fico feliz por seu comprometimento, sei que palavra de caboclo tem seu valor. (Resposta de destituição do argumento: é aceito o contraargumento integralmente, retirando-se, assim, o argumento inicial).

Nos movimentos argumentativos analisados, são identificados argumentos que apresentam pontos de vista pautados em conhecimento pessoal - que têm como base informações de fontes pessoais ou de grupo para deliberar um posicionamento; baseados em julgamento de valor, são argumentos de baseados em veracidade dos dados apresentados seja ele científico ou jurídico. De modo que os estudantes intuitivamente mergulham nos aspectos sociais, morais, éticos e científicos referentes à questão dos impactos que a extração de bauxita na região do Baixo Amazonas.

Nesse sentido, os dados dialogam com posicionamento de Jiménez-Aleixandre e Pereiro-Muñoz (2002), quanto ao desenvolvimento de valores ambientais se referindo à natureza das QSC e os conhecimentos que elas requerem. As mesmas declaram que os valores dão um suporte importante para a emissão de uma opinião, mas que para isso seja feito é necessário também que se tenha o conhecimento conceitual. Desse modo, os valores não se desenvolvem em uma lacuna, como se estivesse desconectado do conhecimento escolar.

Em relação aos elementos do argumento (dados, conhecimento de causa, índices e outros, que servem como base para justificar um posicionamento referente a um ponto de vista) verifica-se que ocorreu um movimento dialógico entre os

4


participantes ao indagar, afirmar ou colocar sua experiência de vida. Assim, os interlocutores (os atores sociais interpretados pelos estudantes) puderam suscitar concordância, discordância, ou até mesmo indiferença aos demais em decorrência de tais argumentos.

Estas ações foram observadas nos momentos de análise dos movimentos argumentativos, dos quais incluem o argumento, o contra-argumento e a resposta (tríade argumentativa A-CA-R), apresentados por Lira e Leitão (2016). Com isso, na Audiência foi possível identificar a intenção comunicativa dos estudantes nos argumentos. Além disso, foi observado que conteúdos diversos foram abordados, presumindo-se que tem sido pesquisado e discutido nos grupos, mas principalmente verificou-se a expressão espontânea do conhecimento que os alunos tinham naquele momento.

\section{CONSIDERAÇÕES FINAIS}

A escolha do tema da atividade proposta, os impactos que a extração de bauxita (óxido de Alumínio) na região do Baixo Amazonas, se mostrou importantíssima para o envolvimento dos alunos, pela apresentação dos argumentos, conflitos dos posicionamentos com as crenças pessoais e pela defesa por meio de conhecimentos técnicos e conceituais.

O debate sobre a extração da Bauxita na região mostrou uma linha tênue entre os fatores sociais e econômicos frente aos impactos causados ao meio ambiente, suscitando a reflexão que os alunos têm sobre si e sobre as ideias que o outro possui, colocando em conflito a moralidade, a ética, a necessidade por emprego e a importância da preservação do meio ambiente, dentre outros aspectos.

A utilização da Audiência Pública Simulada como estratégia de ensino se mostra uma ferramenta útil no ensino das ciências (tanto humanas, como nas exatas), por propiciar o envolvimento dos alunos em movimentos argumentativos, para tratar das Questões Sociocientíficas e ambientais, bem como, inserir o aluno na construção, avaliação e na comunicação do conhecimento. Trata-se de uma dinâmica discursiva ampla, por dispor papéis variados e que possibilita ao estudante a elaboração de um discurso mais aberto e não tão rígido, favorece a participação de todos os estudantes com papéis próprios, e principalmente para abordar questões conflituosas de âmbito socioambiental, em particular a extração da bauxita (óxido de alumínio) como questão geradora para o estudo de conceitos ligados à química, particularmente.

O movimento argumentativo identificado, a figura 1 e a análise realizada dos discursos pela APS, ao abordar as Questões Sociocientíficas e ambientais, nos mostra que os estudantes ficam mais à vontade para se envolver na atividade, pelo fato de se defrontarem com questões de âmbito sociais e ambientais que envolvem a realidade que eles fazem parte.

De um modo geral, conclui-se que esta atividade (de caráter inter e multidisciplinar) envolveu no debate questões socioambientais, promoveu um ambiente para exposição do conhecimento, apresentação do ponto de vista e defesa desse posicionamento, possibilitando um pensamento crítico e a possível ressignificação dos conhecimentos dos alunos. 


\section{Referências}

AZEVEDO, Marcondes Luiz da Silva; SILVA, Márcia Gorette Lima. (2018). Uma proposta para desenvolver a Habilidade Cognitivo-Linguística (Explicar) em aulas de química utilizando a estratégia POE (Prever-Observar-Explicar). Revista de Estudos e Pesquisas sobre Ensino Tecnológico (EDUCITEC), v. 4, n. 08, 2018.

JOHNSON, Ralph; BLAIR, John Anthony. Lógica informal: uma visão geral. EID\&A - Revista Eletrônica de Estudos Integrados em Discurso e Argumentação, v. 1, n. 14, p. 195-215, 28 dez. 2017.

CALZOLARI, Anselmo; MILARÉ, Tathiane; SILVA, Daniel Luiz da. 3A013 "Roleplay" e argumentação em perspectiva dialógica na formação inicial de professores de Ciências. Tecné Episteme y Didaxis: TED, p. 1-6, 2018.

CÉSAR, João Batista Martins. A audiência pública como instrumento de efetivação dos direitos sociais. Revista do Mestrado em Direito da Universidade Católica de Brasília: Escola de Direito, v. 5, n. 2, 2011.

CESCO, Susana. Interdisciplinaridade e temas socioambientais. Estudos avançados, v. 25, n. 72, p. 327-330, 2011.

CHIARO, Sylvia de; LEITÃO, Selma. O papel do professor na construção discursiva da argumentação em sala de aula. Psicologia: reflexão e crítica, v. 18, n. 3, p. 350-357, 2005.

CHION, Andrea Fernanda Revel; MEINARDI, Elsa; ADÚRIZ-BRAVO, Agustín. La argumentación científica escolar: contribución a la comprensión de un modelo complejo de salud y enfermedad. Ciência \& Educação (Bauru), v. 20, n. 4, p. 987-1001, 2014.

JIMENEZ-ALEIXANDRE, M. P.; PEREIRO-MUNOZ, C. Knowledge producers or knowledge consumers. Argumentation and decision making about environmental management, 2002.

JIMÉNEZ-ALEIXANDRE, M. P.10 Ideas clave: Competencias en argumentación y uso de pruebas. Vol. 12. Barcelona: Graó, 2010.

JIMÉNEZ-ALEIXANDRE, M. P.; GALLÁSTEGUI, J. R. Argumentación y uso de pruebas: construcción, evaluación y comunicación de explicaciones en física y química. Didáctica de la Física y la Química. Barcelona: GRAÓ, cap, v. 6, p. 121-139, 2011.

JORGE, A. S., Puig, N. S. Enseñanza de las Ciencias. p. 405. (2010)

LEITÃO, Selma. O Debate Crítico como contexto de desenvolvimento do pensamento reflexivo. Projeto de pesquisa. Recife: Universidade Federal de Pernambuco. 2011.

LIRA, Dowglas Amorim; LEITÃO, Selma. Apropriação da Escrita Argumentativa por Estudantes Universitários. EID\&A-Revista Eletrônica de Estudos Integrados em Discurso e Argumentação, p. 64-83, 2016.

LUDKE, Menga; ANDRE, Marli Dalmazo Afonso de. Pesquisa em Educação Matemática: abordagens qualitativas. $2^{\mathrm{a}}$ ed. São Paulo: Editora EPU, 2013.

15


McSHARRY, Gabrielle; JONES, Sam. Role-play in science teaching and learning. School Science Review, v. 82, p. 73-82, 2000.

MENDONÇA, Paula Cristina Cardoso; Justi, Rosária da Silva. EnsinoAprendizagem de Ciências e Argumentação: Discussões e Questões Atuais. Revista Brasileira de Pesquisa em Educação em Ciências, v. 13, n. 1, p. 187216, 2013.

MITCHELL, Gordon R. Simulated public argument as a pedagogical play on worlds. Argumentation and Advocacy, v. 36, n. 3, p. 134-150, 2000.

MONTEIRO, Licio Caetano Rego. A "audiência pública simulada" em sala de aula como prática para abordar conflitos territoriais. Revista de Geografia do Colégio Pedro II, v. 3, n. 6, p. 81-90, 2018.

MORAES, R.; GALIAZZI, M. C. Análise Textual Discursiva. 2. ed. rev. Ijuí: UNIJUÍ, 2007.

PENHA, Sidnei Pércia da. Atividades Sociocientíficas em sala de aula de Física: as argumentações dos estudantes.2012. 485 f. Universidade de São Paulo. São Paulo-SP. 2012.

PERELMAN, C. Retóricas. 2. ed. São Paulo: Martins Fontes, 2004.

SADLER, Troy D. Informal reasoning regarding socioscientific issues: A critical review of research. Journal of Research in Science Teaching: The Official Journal of the National Association for Research in Science Teaching, v. 41, n. 5, p. 513-536, 2004.

SANTOS, Wildson Luiz dos Pereira. Educação científica humanística em uma perspectiva freireana: resgatando a função do ensino de CTS. Alexandria: revista de educação em ciência e tecnologia, v. 1, n. 1, p. 109-131, 2008.

SASSERON, Lúcia Helena. Alfabetização Científica no Ensino Fundamental: Estrutura e Indicadores deste processo em sala de aula. 2008. 265 f. Tese (Doutorado - Programa de Pós-Graduação em Educação. Área de Concentração: Ensino de Ciências e Matemática) - Faculdade de Educação da Universidade de São Paulo. 2008.

SILVA, Marcela Gomes; MEDEIROS, Edilene Ferreira; SILVA, Márcia Gorette Lima. A qualidade dos argumentos em uma atividade de resolução de questão sociocientífica em aulas de biologia. Enseñanza de las ciencias, n. Extra, p. 4575-4580, 2017.

SILVA, Marcela Gomes da. A escassez de água na caatinga: uma questão sociocientífica para desenvolver habilidades argumentativas nas aulas de biologia. 2017. 112 f. Dissertação (Mestrado Profissional em Ensino de Ciências Naturais e Matemática) - Centro de Ciências Exatas e da Terra, Universidade Federal do Rio Grande do Norte, Natal, 2017.

SIMONNEAUX, L. Argumentation in socio-scientific contexts. In: Erduran, S., Jiménez-Aleixandre, M. P. (Eds). Argumentation in Science Education: Perspectives from classroom- Based Research. USA, Tallahasse: Springer, p. 179-199, 2007.

TOULMIN, S. E. Os usos do argumento. $2^{a}$ edição. São Paulo: Martins Fontes. 2006.

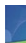


ZEIDLER, Dana L.et al. Beyond STS: a research-based framework for socioscientific issues education. Science Education, v. 89, n. 3, p. 357-377, 2005.

Recebido: 05/03/20

Aprovado: $27 / 05 / 20$

Como citar: AZEVEDO, M. L. S.; ARAÚJO, I. A. F; PINHEIRO, A. J. Audiência pública simulada: uma ferramenta multidisciplinar para o ensino de Ciências envolvendo questões sociocientíficas e ambientais na região Amazônica. Revista de Estudos e Pesquisa sobre Ensino Tecnológico (EDUCITEC), v. 6, Edição Especial, e119720, 2020.

Direito autoral: Este artigo está licenciado sob os termos da Licença Creative CommonsAtribuição 4.0 Internacional.

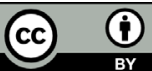

